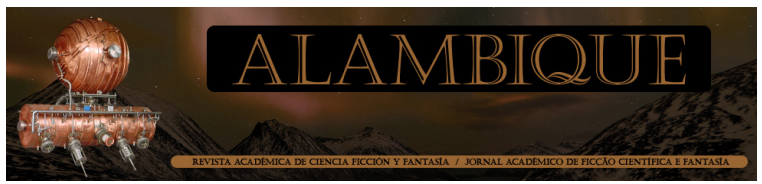

Volume 1 | Issue 1

Article 3

\title{
Yo, Ciborg: el andamiaje político de la subjetividad y de la otredad en la ciencia- ficción argentina
}

Silvia Gabriela Kurlat Ares

Independent Scholar, silviakares@hotmail.com

Follow this and additional works at: https://scholarcommons.usf.edu/alambique

Part of the Latin American Languages and Societies Commons, Latin American $\underline{\text { Literature Commons, }} \underline{\text { Modern Literature Commons, and the Other Arts and Humanities }}$ $\underline{\text { Commons }}$

Recommended Citation

Kurlat Ares, Silvia Gabriela (2013) "Yo, Ciborg: el andamiaje político de la subjetividad y de la otredad en la cienciaficción argentina," Alambique: Revista académica de ciencia ficción y fantasia / Jornal acadêmico de ficção científica e fantasia: Vol. 1 : Iss. 1 , Article 3.

DOI: http://dx.doi.org/10.5038/2167-6577.1.1.3

Available at: https://scholarcommons.usf.edu/alambique/vol1/iss1/3 


\title{
Yo, ciborg: el andamiaje político de la subjetividad y de la otredad en la ciencia ficción argentina
}

\author{
Silvia G. Kurlat Ares \\ Independent Scholar
}

\section{Introducción}

La ciencia ficción argentina ha articulado desde sus inicios no sólo una fuerte crítica de lo social sino también un espacio de reflexión ideológica, si nada más, por aquello que decía Frederic Jameson sobre cómo la ciencia ficción hace transparente nuestra experiencia ideológica del presente a través de un proceso de extrañamiento cognitivo. Bien por accidente bien por búsquedas más conscientes, a partir de la década de 1970, emerge cada vez con mayor claridad una ciencia ficción que organiza desde muy distintos medios y perspectivas una reflexión sobre los elementos que constituyen el andamiaje ideológico del discurso letrado. Ese basamento, de algún modo, constituía el sentido común del campo cultural argentino desde hacía al menos dos décadas y todavía imaginaba a la otredad del Pueblo como una entidad homogénea. Es en las indagaciones en torno a las definiciones de esa otredad donde la ciencia ficción experimentará (aunque no siempre en forma fructífera) con los elementos que construyen esas estructuras, poniendo a prueba distintas formas de orden político y de gobierno, y haciendo evidente que la diversidad es una amenaza a la hegemonía política y cultural, más allá del signo político que ésta ostente o de sus mentadas pretensiones democráticas. Así pues, el presente trabajo analiza cómo operan esas construcciones ideológicas al examinar el papel de los monstruos, los extraterrestres y de los ciborgs que aparecen en la ciencia ficción argentina, con independencia de los medios y los lenguajes con que esa reflexión se haga. Por este motivo, en las próximas páginas, nos centraremos en una historieta como Yo, ciborg de Grassi y Olivera, quizás una de las más representativas de lo que se dio en llamar el barroquismo de la historieta de ciencia ficción argentina. Tomar una historieta de ciencia ficción intenta subrayar primero la emergencia temprana de un tema central de discusión político-ideológica dentro del campo cultural argentino a través del que sería uno de sus nudos fuertes, es decir, la formación del sistema de identificaciones del populismo. En este sentido, la historieta es notable ya que aparece en el momento en que esa discusión todavía no está cerrada y su vocabulario está todavía en formación. La misma doble marginalidad ${ }^{\mathrm{i}}$ del artefacto en cuestión (un producto del medio historieta en la modalidad ciencia ficción) hace posible analizar con particular transparencia la fluidez y las paradojas de ese mismo debate. Por esta misma razón, en segundo lugar, esta historieta permite analizar cómo y cuáles son los elementos que participarían en la rearticulación del sujeto social central para el discurso político contemporáneo.

\section{Yo, ciborg: Una historieta en el campo cultural.}

Yo, ciborg es un artefacto inusual dentro de la ciencia ficción argentina ya que representa uno de los pocos casos de ciencia ficción dura realmente articulado como tal $\mathrm{y}$, además, exitoso en su factura, pese a las complejas contradicciones que conforman su 
armazón ideológica y que serán uno de los objetos de este trabajo. Escrita por Alfredo Grassi (1925) e ilustrada por Lucho Olivera (1942- 2005), fue publicada originalmente como serie en mayo de 1978 en los números 42 a 49 de Skorpio Gran Color (1974-1996), una revista de la editorial Record. En 1991, la empresa volvió a imprimir la historieta en un solo volumen como suplemento para la misma revista. La historieta presenta hermosas ilustraciones en blanco y negro, en trazos a veces violentos donde suelen jugar los borrados, generando imágenes visualmente dinámicas que se apoyan en gran medida en el uso de grandes diagonales y del contraste. En las viñetas, los espacios positivos son compactos y abigarrados, pero luminosos, en violenta oposición a los espacios negativos, que aparecen saturados por sombras. Si bien la narración mantiene cierta linearidad, a medida que la fábula se desarrolla, los espacios entre las viñetas aparecen rotos o desgarrados cada vez con mayor frecuencia, y las transiciones de viñeta a viñeta parecen probar todas las formas organizativas que el medio ha ensayado a través de su historia. En sus 106 planchas, la historieta parece hacer un collage de todos los recursos técnicos a su alcance, incluyendo el uso de múltiples cuadros escalonados y de la lectura circular. Lo que empieza como una historieta clásica con una narración organizada en una estructura de viñeta a viñeta, se va desarticulando con la pérdida de marcos y desplazamientos en la plancha, hasta que finalmente una imagen única ocupa todo el espacio. Con una fuerte influencia de Héctor G. Oesterheld (1919- 1978?) y del pathos narrativo de la ciencia ficción norteamericana de la década del cincuenta, la fábula se centra en Hoc, un soldado terrestre, durante una guerra contra Marte en el año 2265. Cuando Hoc intenta escapar del Vehículo (una suerte de universo, hogar, y máquina de guerra ${ }^{\mathrm{ii}}$, descubre que es un ciborg que ha perdido su cuerpo biológico y que no está defendiendo la Tierra, tal como le dijeran sus superiores y donde cree estar al iniciarse la historia (plancha 4), sino que es parte de una fuerza de invasión terrícola en Marte (plancha 11). Pasmado ante las mentiras que creyera tan dócilmente, se rebela, y se une a las fuerzas defensoras marcianas para finalmente convertirse en su líder. Hoc triunfa y logra detener la invasión terrestre cuando revierte el sistema ecológico marciano a su estado original en una traición final a sus propios coterráneos. Por una parte, la lucha de Hoc explora la relación de la guerra con la ecología puesto que los desplazamientos de Hoc revelan un Marte desahuciado. Por otra, ese combate pone en escena preguntas en torno a la naturaleza humana no sólo en términos biológicos sino éticos, ya que la segunda dimensión del relato sigue la búsqueda del cuerpo perdido de Hoc y la recuperación de su humanidad en un sentido completamente literal: Hoc descubre que antes de ser un ciborg fue un ser humano (planchas 17 y 24). Durante su enfrentamiento con la computadora que dirige Vehículo, ésta claramente le informa que "Tú eres humano-Hoc. Tu cerebro es humano" (plancha 26, viñeta 1). Ese descubrimiento dispara la búsqueda del cuerpo perdido, aunque no será sino hasta el final cuando Hoc descubra que él ha sido responsable de su propio destino artificial. El cuerpo hiper- masculino de Hoc y su búsqueda de una identidad esencial cuyo sino es contrario a su configuración ciborg, construye un contra- argumento temprano a lo que Haraway describirá mucho después como el locus de una identidad "not afraid of permanently partial identities" (Haraway, 1991:155). No sólo eso, sino que la historieta entera reniega por adelantado de la idea de poshumanidad tal y como fuera planteada por Hayles (Hayles, 1999) ya que los destinos humano y cibernético de Hoc operan como antípodas ideológicas. La historieta, más bien, hace una suerte de hipótesis anticipada de las reflexiones de Manuel Castells al 
describir la emergencia de identidades que se consolidan en una imaginaria resistencia a la expansión del capitalismo, en la confrontación entre el Ser y la Red (Castells, 1997). La búsqueda de Hoc puede ser descripta como un intento de establecer una vida más allá de las normativas del imperio [terrestre], puesto que

there is life beyond the network society: in the fundamentalist cultural communes that reject dominant values and build autonomously the sources of their own meaning; sometimes around self-constructed alternative utopias; more often, around the transcendent truths of God, Nation, Family, Ethnicity, and Territoriality. (Castells 2001: 170)

En el caso que nos ocupa, los orígenes de esa identidad comunal pueden buscarse en las tradiciones mismas del campo cultural argentino que ha sido particularmente desconfiado de las nuevas tecnologías. J. Andrew Brown señala que en Argentina existe una larga tradición de equiparar nuevas tecnologías con la pérdida de una identidad esencial (Brown, 2010) y yo misma he analizado en otro trabajo la historia de ese proceso (Kurlat Ares, 2011), así que no quisiera insistir sobre este punto. Más bien, es necesario subrayar que en esta historieta, la búsqueda de Hoc implica una regeneración ontológica absoluta. La recuperación del cuerpo biológico, imagina el ciborg Hoc, implica recuperar la soberanía del Yo a través de las virtudes humanas porque ser hombre es la síntesis de la naturaleza y el espíritu. Ese es el primer indicio de la presencia de algunos aspectos del pensamiento krausista ${ }^{\text {iii }}$ que la historieta retoma para intentar una compleja meditación sobre cuál es la relación entre lo biológico y lo social, y entre lo absoluto de la razón y lo contingente y finito de la individualidad. El fuerte componente ético de las acciones de Hoc, aún en sus violentas contradicciones, parece operar como una suerte de prolongación del imaginario romántico dentro de la renovación del ideario populista que marcó la Argentina de los setenta y que se ha hecho realidad en el ideario político contemporáneo.

\section{Lecturas políticas en red: la emergencia del nuevo Otro}

Yo, ciborg hace una lectura temprana de fenómenos ideológicos que no se manifestarán en forma abierta en el campo cultural argentino sino hasta mucho más tarde. Producto de un intrincado proceso, la historieta da cuenta de la emergencia de una nueva forma de otredad política. Desde los cincuenta, la historieta argentina había establecido una audiencia madura, interesada en temas políticos y en consumir materiales estéticos de creciente complejidad visual y narrativa. Los setenta encontraron a la historieta intentando contestar dos preguntas que eran parte de un debate mayor en el campo cultural argentino: cómo definir "lo nacional" y cómo narrar la formación de diversas subjetividades en espacios culturales marcados por una creciente polarización política, aunque esas diferencias abrevaran en aguas ideológicas comunes. Lo paradójico de esta situación requiere una breve aclaración: pese a la aparente diversidad de apuestas políticas del campo cultural argentino, las mismas compartían un tronco ideológico común con raíces en el nacionalismo y en el populismo ${ }^{\text {iv }}$ que, aún en sus violentas divergencias, acabó por generar un concepto de otredad harto particular. Tras abandonar poco a poco el imaginario de los indígenas y de los inmigrantes que había sido la 
preocupación clave del pasaje a la Argentina contemporánea, emerge un Otro que se convierte en el interlocutor central y deseado del campo cultural argentino. Ese Otro tomaría cuerpo en el imaginario de la izquierda derrotada de los setenta a través de la narrativa testimonial e histórica de la década siguiente ${ }^{\mathrm{v}}$. Su identidad estaría anclada en la memoria histórica reciente aunque no fuera realmente formulada en los términos de la multiplicidad de esas mismas experiencias ni en la diversidad de la población ni tan siquiera en la cambiante metamorfosis de la política cotidiana. La identidad de este Otro contestatario se construiría en el mundo de las utopías de absoluto y en sus fracasos. Por ende, compartiría con esos programas políticos, sus marcadores y sus horizontes ideológicos: este será un Otro revolucionario, masculino, blanco, que pertenece a una izquierda indefinible, de raíz cristiana, homogénea y, en apariencia, sin conflictos internos violentos. Sin embargo, las formas tempranas de ese Otro aparecen en el campo cultural mucho antes y pueden rastrearse en la ciencia ficción, donde todas esas problemáticas y contradicciones hacen a la construcción de nuevas formas identitarias en textos como el que analizamos aquí. Este es un Otro que es lo Uno y los Muchos, sin más identidad que su propia derrota hecha heroica por virtud de su propia buena voluntad, y por lo tanto, moralmente correcta a priori. Esta otredad que será a la vez hegemónica (excúseme el oxímoron) se constituyó como la voz de los oprimidos y por propiedad transitiva, en la voz del Pueblo ahora convertido en muchedumbre, aun cuando las traducciones de las definiciones clásicas de Pueblo fuesen algo confusas en su pasaje al nuevo marco de referencias ideológicas y aun cuando el Pueblo como sujeto fuese puesto en tela de juicio en la misma década del setenta ${ }^{\mathrm{vi}}$. Esas operaciones condensan la emergencia de un nuevo populismo para el cual, como claramente señala Jon Beasley Murray, el objeto más inmediato es resolver el tema de la identidad nacional sin necesariamente desarrollarlo más allá de la representación (Beasley Murray, 2010: 47). La cuestión de la representación que originalmente se había organizado en torno a la dicotomía amigo/ enemigo, ahora se volverá mucho más compleja al tener que definir no sólo quiénes integran el nosotros y quiénes son los otros (y quiénes son los enemigos), sino cómo y quiénes se identifican con los proyectos nacionales que se emiten desde el poder. Para inicios del nuevo siglo, no caben dudas de que en el centro del campo cultural esta nueva otredad derrotada que ahora ostentaba el poder ${ }^{\text {vii }}$, constituye un verdadero núcleo ideológico en gran parte de la producción cultural argentina. Entiéndase bien: este Otro no es Otro en sentido diferenciado por etnia, religión, género, o tan siquiera ideología, porque es el Otro que se ha fusionado con el Nosotros del discurso populista que recorre todo el campo cultural desde mediados de la década del cincuenta. Es más, en los raros casos en que la diversidad étnica que presentaría, por ejemplo, la población indígena argentina reapareció en la producción cultural durante los últimos veinte años, se trata de indígenas imaginarios y sumamente estilizados: su misma existencia está anclada en operaciones simétricas a las realizadas cien años antes por la elite intelectual que proyectó el país, esta vez, escogiendo las virtudes de la barbarie en lugar de las de civilización como un modo de adscribirse y redefinir al Pueblo viii. Podría argüirse (como se ha hecho), que tal operación recupera sujetos perdidos para el discurso letrado y que no no es más que la inversión de los polos negativo/ positivo de los valores del discurso liberal que había expulsado a la otredad del Pueblo del discurso sobre la Nación, ya que no parecía ajustarse a los requisitos del idealizado modelo de Estado-Nación decimonónico $^{\text {ix }}$. Pero al mismo tiempo, cabe preguntarse, primero, no sólo por qué 
ocurrió sino cómo fue posible una operación que redefine la otredad en términos expurgatorios y deseados a la vez. Y, además, cabe cuestionarse por qué objetos culturales que intentan redefinir la identidad en términos que evocan valores democráticos recurren al vocabulario y a la ideología de los esencialismos finiseculares. La articulación de esa relación entre el Nosotros y la otredad sólo era válida en la medida en que constituyera una hegemonía basada en intereses y alianzas coyunturales aunque no fuesen percibidos como tales. Cualquier cuestionamiento de esas alianzas generaba un violento rechazo. Así pues, preguntarse sobre cómo se generaron esos discursos identitarios no es vano, especialmente, en vistas del creciente empobrecimiento de amplios sectores de población ya carenciados, de políticas étnicas si no francamente discriminatorias al menos tolerantes de tales conductas, y de los crecientes índices de violencia de género, entre otros muchos indicadores de que las nuevas alternativas ideológicas también estaban realizando operaciones ideológicas expurgatorias con muchos de los sujetos que parecía defender. Ese Otro/ Nosotros deseado se proyectaba cada vez más sobre la singularidad imaginaria de narrativas de estado (y sobre el estado) que negaban la diferencia, convirtiendo la relación entre Uno- Otro en una pura entelequia, aun cuando esa realidad era puramente circunstancial.

Es justamente en Yo, ciborg donde se narra de manera más condensada y clara cómo emerge esa otredad ${ }^{\mathrm{x}}$ de nuevo cuño, o más bien, cómo los rasgos que la constituyen (su acervada masculinidad, su nacionalismo antiimperialista novecentista, su desdén por la diversidad y el pluralismo, su claro anti-intelectualismo, su preferencia por la acción antes que por la reflexión) reponen con nuevos bríos en el debate político la rearticulación del populismo. Así, es necesario analizar esa otredad que aparece como conflictiva y conflictuada frente a una singularidad que, lejos de rechazarla, la desea e intenta mimetizarse con ella. En una primera lectura, ese conflicto surge como una confrontación de valores entre los universos del nosotros y de los ellos (sic), lo cual ciertamente no era insólito en 1978, cuando esta historieta intenta brindar una clara narrativa de oposición al discurso ultramontano de la dictadura (1976-1983): Hoc se rebela contra el militarismo y el imperialismo terrestres y se une a la justa causa de liberación/ independencia marciana porque "siente que su espíritu está junto a ellos" (plancha 13, viñeta 2). Pero no es tan claro por qué esa divisoria de aguas ahoga las diferencias entre espacios identitarios cuando, desparecida la dictadura, esa misma lectura pareciera ofrecer los fundamentos del finalmente triunfante Otro "canónico" en unos términos que ponen en tela de juicio la ética de su aparente llamado a la diversidad.

Todavía más curioso es que esta historieta elija explorar estas cuestiones a través de los ojos de un ciborg, un ser que no es ni humano ni máquina y que por ende, en su misma ambigüedad parezca legitimar toda forma de diversidad. Desde al menos mediados de los sesenta, los trabajos de astronáutica han explorado la idea del ciborg como instrumento útil para la exploración del espacio dadas las dificultades que los humanos enfrentarían en tales empresas. El ciborg fue originalmente concebido como una herramienta $\mathrm{y}$, sin embargo, conservó su aspecto biológico porque su cerebro era humano: esta es exactamente la constitución física de Hoc con su cerebro humano y su cuerpo mecánico. Su hibridez se construye a partir de la concepción decimonónica de la necesidad de dominar el mundo natural a través de la mecanización y explotación de diversos recursos. No se trata simplemente de la imagen del fantasma-en-la-máquina, 
puesto que Hoc rechaza todo proyecto de hibridación/ multiplicidad, para intentar reponer la pureza intocada del cuerpo biológico. En palabras de Jameson:

The reincorporation of organic material in the imagery of the cyborg [...] tends to transform the organic into a machine far more than it organizes machinery. Thus, postmodern or cybernetic technology becomes if anything even more unnatural than the older heavy- industrial kind (Jameson, 2005:64).

Esta mirada horrorizada sumada a la vieja hipótesis del ciborg como instrumento amenazante es el andamiaje arquitectónico de la historieta. Tanto estas perspectivas como la noción de ingeniería planetaria que recorren la historieta sustentan el argumento de leer Yo, ciborg entre los muy pocos ejemplos de ciencia ficción dura jamás producidos en Argentina, aún en una forma bastante particular y tangencial. Pero esa definición es muy problemática, ya que la historieta se hace cargo (en forma por cierto contradictoria) de largas tradiciones antitecnologicistas y anticientíficas del campo letrado no sólo en los conflictos internos de Hoc que veremos a continuación, sino también en la evaluación del conocimiento, en la mirada sobre el impacto de las nuevas tecnologías sobre el medioambiente, y en la evaluación de la actividad científica misma. Esas actitudes están condensadas en la reacción de Hoc ante su propio cuerpo ciborg, ya que él ignora completamente su naturaleza tecnológica: no sólo la descubre por accidente y la desprecia, sino que una vez descubierta, todos sus esfuerzos están dirigidos a recuperar su cuerpo humano y a destruir su lado tecnológico a pesar de las claras ventajas que le ofrece. Si esa primera reacción puede ser leída como el horror ante el descubrimiento de una identidad falseada, una mirada más atenta muestra que lo que recorre las búsquedas de Hoc es una voluntad de reponer valores vagamente espirituales en un espacio marcado por la guerra, la tecnología y la contaminación del medioambiente. Sin embargo, esos valores no se reponen desde su propio sistema: el vitalismo de Hoc lo lleva a asesinar al jefe de la ciudad de Sep Namúxi ${ }^{\text {, }}$ su desprecio hacia la tecnología le impide acceder a forma alguna de conocimiento, y para resolver la invasión terrestre, Hoc recurre también al genocidio. Como veremos en las siguientes páginas, pese a que toda la historieta intenta oponer los valores de la cultura y la comunidad a los valores de la industria y la sociedad, las contradicciones en las que incurre son de tal peso que su armazón ideológica implotará, aún y a pesar de la articulación exitosa del Otro como subjetividad política incorporada o embebida en el Nosotros.

\section{Los límites de la identidad}

Hoc vive en un límite inestable, a medias entre lo biológico y lo tecnológico, pero también tensionado entre lealtades, conocimientos, y éticas: esa posición verdaderamente precaria es el punto de partida de su rebelión, aunque finalmente la resolución no vendrá de respuestas balanceadas ni de su búsqueda. La historieta provee un imaginario complejo precisamente porque al no ser dueño de propio cuerpo, toda alianza trazada por el ciborg apenas sí tendrá fundamento: Hoc no comparte con los terrestres sus valores culturales ni desea retornar a un mundo que sólo lo verá como un monstruo o como una herramienta, pero tampoco puede integrase al universo cultural marciano porque es 
humano: ese es su grito de guerra a lo largo de buena parte del relato. Pese a ser el libertador, pese a su ética, el ciborg Hoc es tanto un extraño a la sociedad civilizada como un monstruo que no pertenece al universo de lo bárbaro en un sentido clásico. Alienado de la Tierra y de Marte, su identidad se construye como una forma de extrañamiento. Errante en un paisaje pedregoso y yermo, Hoc reza

Solo. Ajeno a lo creado, ausente a lo que me destinaste cuando trazaste mi destino... Un monstruo para los seres del lejano planeta verde... un monstruo para los habitantes de este planeta rojo... con una mente que sufre y un cuerpo que no es el mío (plancha 43, viñetas 1 y 2 )

Los extraterrestres y los ciborgs de la ciencia ficción son en gran medida una proyección de la experiencia del Otro más que una otredad radicalmente distinta que no puede ser realmente aprehendida. Sus cuerpos cuestionan no sólo lo normalmente asumido acerca de las relaciones sexuales y sociales, sino también nociones sobre el conocimiento, la propiedad, la autonomía, y el libre albedrío (Freedman, 2000; Suvin, 1979). Los desplazamientos de Hoc ofrecen una suerte de espiral ascendente a través de esas temáticas para culminar con el rescate de su cuerpo. Extrañamente, esas experiencias nunca ofrecen la oportunidad de conocer o de aprehender algo a pesar de que Hoc circula por espacios simbólicos de gran complejidad donde enfrenta diferentes formas de saber. La mirada de Hoc es ciega a nada que no sea recobrar el cuerpo perdido y vengarse de la situación en que se encuentra. Así, nos encontramos frente a un cuerpo híbrido que reniega de la hibridez, frente a un ciudadano naturalizado que renuncia a su patria de adopción, y frente a una eticista que prefiere la práctica subjetiva de la acción para construir valores absolutos. De este modo, recuperar el cuerpo humano se constituye como una negación de elecciones y como una pérdida de la hibridez [del cuerpo ciborg] así como de todas las posibilidades que éste ofrece. Sin embargo, la historieta se resiste a una lectura ideológica simplista anclada únicamente en una línea de lectura que sugiera que esas pérdidas son una vuelta sobre una forma de la singularidad de lo Uno o un retorno a la Edad de Oro perdida que se articula en otras historietas de esa misma década.

Es interesante analizar las contradicciones que emergen de las negativas de Hoc: esas negativas ponen en escena formas de pensamiento organicista porque la negatividad de lo híbrido marca el horizonte de lectura y porque la fábula entera esté dirigida a reconvertir lo "humano" en términos de alianzas políticas con los oprimidos a cualquier costo, sin que ésto signifique poner en escena formas de empatía o, tan siquiera, las necesidades de esos mismos oprimidos ${ }^{\mathrm{xii}}$. En dos escenas Hoc tiene la oportunidad de trazar alianzas comunitarias que le ofrezcan la posibilidad de reorganizar su sistema de pertenencia y, en ambos casos el intento fracasa. El primer intento se lo ofrece el robot Wanamin de Ciudad Muerta cuando Hoc es capturado y llevado a la ciudad ambulante. Pero Hoc nunca intenta conocer a sus habitantes mecánicos o entender sus experimentos biológicos, sino utilizarlos en la obsesiva misión que se ha impuesto. Lo mismo sucede con los soldados que finalmente lo rescatan de la ciudad: incapaz de establecer lazos de amistad con otros humanos, puede perdonarle la vida a quien lo rescata como forma de pago, pero no puede establecer lazos duraderos de amistad o solidaridad. Este tipo de contradicciones hacen falaz la rebelión de Hoc pues opera dentro de los límites de opciones morales totalizantes $y$, por ende, excluyen toda posibilidad de existencia de una 
otredad genuina con quien dialogar. Si Hoc intenta mostrar una suerte de mapa hacia la perfección de lo divino a través de la razón, la articulación de ese trazado deja bastante qué desear ya que aquí lo divino aparece como una fuerza devastadora y vengativa cuya racionalidad está mucho más atada a lo contingente de lo personal (la venganza, encontrar el cuerpo) que a una lógica racional. Así, las acciones de Hoc establecen la idea de que lo Uno sólo se reconoce en la más absoluta identidad y singularidad. En el mismo instante en que Hoc recupera su cuerpo biológico y vuelve a ser humano, se transforma otra vez en un invasor primordial: el topo que no puede ser distinguido de los nativos y es, a pesar de todo, un extraño. Cierto: es un espacio ambiguo, construido sobre elecciones éticas personales. Pero el ciborg Hoc es un ser conflictuado mientras que el humano Hoc es la encarnación mítica de la virtud absoluta: recuperar la esencia humana para mejor elegir desde virtudes cardinales, implica ser un paria (plancha 101, viñeta 6). Pero ese paria es portador de todos los rasgos distintivos de la legitimidad absoluta: es en realidad por este motivo que no pertenece a ningún espacio ni puede trazar alianza alguna ya que, en el final, adscribirse al espacio de Marte o al de la Tierra implica escoger entre proyectos comunitarios o proyectos políticos, implica organizar los lazos de una sociabilidad basada en la solidaridad o en la negociación. La iconografía de ese instante de revelación es clara. Tanto el splash panel que opera de tapa del volumen (y del momento de revelación del destino en tanto que venganza) como los paneles que describen la decisión final de Hoc apelan a poner en escena la búsqueda de una trascendencia de absoluto a través de la unidad del Yo que se despliega como un estallido donde todas las otras potencialidades (sociales, culturales) de Hoc han desaparecido para ser reemplazadas por el imaginario de la esencia y la continuidad apelando a algunos elementos de lo que en filosofía suele discutirse como el criterio biológico de identidad. Este criterio se opone (y complementa, en parte), a la cambiante psicología y roles de la persona no sólo a largo de una vida, sino a lo largo de un día. Pensar la identidad en términos biológicos permite pensar la cuestión en términos de la materialidad del cuerpo, tal y como Hoc parece estar haciendo aquí. La persistencia de la identidad a través del tiempo independientemente de las circunstancias permiten pensar la continuidad de las preocupaciones y de las acciones desde una perspectiva ética. Tal y como Hoc escenifica, sin embargo, el transplante de su cerebro a otro cuerpo delata algunas de las fisuras de este razonamiento, ya que el ciborg Hoc paga con su vida los errores de los cuales es $v_{\text {víctima }}{ }^{x i i}$. Es posible analizar toda la historieta desde la perspectiva que abren esas contradicciones ya que subrayan las mismas problemáticas que aparecen en otros lugares de la fábula. Para los fines d nuestro análisis, debemos detenernos en la imagen de la tapa. Allí, Hoc enfrenta su propio cerebro sobredimensionado, mecanizado, y dividido, enmascarado tras su propio rostro ciego. En la última plancha, en cambio, en una larga diagonal construida sobre el contraste de espacios negativos y positivos, una larga fila de Hocs camina hacia el lector casi pisando las cabezas de los viejos dioses olvidados que pueblan el último cuadro, imponiendo sobre los espacios negativos la materialidad del cuerpo humano que finalmente ha llegado a Marte. Si la primera imagen habla del astillamiento del sujeto híbrido, la última proclama la singularidad triunfante de la identidad anclada en el cuerpo [masculino] recuperado. Los últimos cuadros apelan, además, tanto a la iconografía del cristianismo (aparece Hoc-hombre cargando su cuerpo ciborg sacrificado y bajando, ya iluminado, la montaña de los sabios) como a la de la lealtad y la traición (Hoc finalmente mata a Loch, el jefe de la invasión a Marte, pero 
también su mejor amigo). Esa doble apelación juega también a apuntalar una identidad completamente singular que termina por socavar la aparente virtud de la deslealtad de Hoc, pero también la imaginaria defensa de la diversidad marciana. Así pues, la discusión en torno a ser humano parece centrarse completamente en las dicotomías entre Imperio y Tribu, y entre lealtad y venganza. Aquí no hay lugar para la mezcla de razas o de conocimientos marcianos y terrestres, no hay espacio para el entendimiento mutuo, no hay implicación alguna de las políticas de heterogeneidad. Es la negación del diálogo democrático y de la diversidad social. Sería tentador imaginar que la historieta ofrece una lectura contestaria a los rápidos procesos de modernización que marcaron la Argentina de los años sesenta y setenta. Sin embargo, todo su vocabulario verbo-visual reorganiza los imaginarios marcianos del pulp americano para poner en escena la deificación del individualismo más extremo. Apenas sí velado por una crítica sesgada a la expansión capitalista en los países del Tercer Mundo, la búsqueda de Hoc es la puesta en escena de una subjetividad construida en el autoritarismo, la violencia, y una dudosa superioridad espiritual.

\section{Hoc y los otros: la diferencia como pecado político}

Esa tensión entre la potencialidad creativa de la diversidad y su negación, también aparece en la variedad de razas que pueblan Marte puesto que parecen oponerse a la aparente homogeneidad terrestre que, a través de la violencia, intenta imponer su modelo político sobre ese mundo devastado. En la historieta, Marte se convierte en el escenario de una catástrofe ecológica que ha revertido a sus antiquísimas sociedades a una Edad de Bronce hiper-tecnologizada. Marte es el locus de la imposibilidad del desarrollo social y de la anulación del devenir histórico. Las diferentes razas marcianas ofrecen a la historieta la posibilidad de intentar reflexionar sobre la pregunta acerca de "lo nacional" que, como ya hemos mencionado, corroe a gran parte del parte campo cultural argentino. Si la pregunta por los proyectos nacionales implicaba una búsqueda de sujetos capaces de llevarlos a cabo, será necesario re-definirlos ante la implosión de la historia ${ }^{\text {xiv }}$ que narra este retorno al pasado pre-industrial. Los marcianos no representan pueblos realmente diferenciados sino que son encarnaciones de los ubicuos bárbaros que pueblan la literatura argentina del siglo XIX. La historieta explora varios lugares comunes de esas descripciones: el buen salvaje (el ya mencionado robot Wanamin que salva a Hoc), el salvaje primitivo (los habitantes de la ciudad de Sep Namú que dirigen la resistencia a la invasión, a quienes Hoc acaba por dirigir, y que serán diezmados por una bomba neutrónica) y el salvaje degenerado (los Ogr-Ur que son también mutantes en su propio planeta). En este sentido, la otredad marciana viene a actualizar una mirada sobre el sujeto- nación que de alguna manera ya está presente en el campo cultural, aunque aquí se lo narre desde una perspectiva sesgada y aparentemente empatética. No es el caso: aunque es una operación que parece estar citando la controversia de Valladolid de $1550^{\mathrm{xv}}$, el siglo XIX es el horizonte de referencia del texto puesto que los marcianos son, a su modo, niños, y su hogar, el vacío paisaje marciano, un espacio de lo sagrado, cuyo secreto esplendor yace latente bajo las rojas arenas calcinadas, listo a retornar en toda su salvaje crueldad y castigar a los invasores y a los traidores que lo han mancillado: la venganza humana de Hoc (lo contingente de la individualidad) es la contracara de la venganza cósmica de Marte (lo absoluto de la razón divina). Sin embargo, los marcianos, 
las víctimas de la invasión, no son los dueños de sus propios destinos: el asesinato casi ritual del viejo jefe de Sep Namú no trae un nuevo orden ni repone una Edad de Oro, sino que autoriza el uso de la historia marciana para lo fines de Hoc. Que estos fines tengan la trascendencia de una ética absoluta es, como ya hemos visto, cuando menos, discutible. Ese imaginario del vitalismo como pretexto tanto de las acciones de Hoc como de la agonía social y cultural marciana se expresa en todos los niveles de la narrativa de la historieta. Allí donde los marcianos no pueden pelear por su planeta ni pueden adaptarse a las cambiantes condiciones atmosféricas dentro y fuera de las máquinas de guerra, el héroe no parece tener mayores problemas ni con la variedad de enemigos ni con todos los posibles cambios ambientales aunque sea extramarciano. Las ciudades están muertas y abandonadas sin que los seres mecánicos que las habitan sepan o recuerden cuáles eran sus objetivos y misiones. Las pocas nativas que se ven en la historieta son blancas, están apenas si vestidas, y siempre aparecen en actitud de sometimiento: la historieta parece ofrecer el catálogo completo de los prejuicios coloniales sobre el Otro al mismo tiempo que lo construye como sujeto deseable. Pero ese sujeto está lejos de seguir el modelo lascasiano en sentido estricto o de adscribirse a modelos antropológicos más contemporáneos. Ese catálogo sobre lo otro está allí como un indicador de sujetos- Otros pasados, como una suerte de marcador ideológico de lo ya ido, y para mejor subrayar la formación de una nueva subjetividad encarnada en Hoc.

Así pues, las diferentes razas marcianas son otros tantos ejemplos de una tipología naturalista que permite entrever que desde la ideología textual, los contactos entre culturas se resuelven casi siempre a través de la guerra. Por definición, la historieta asume que los Otros son los derrotados pese a que la guerra no haya terminado, y que las acciones de Hoc no sólo ayudan a los marcianos, sino que los redimen más allá de la muerte. Los salvajes no tienen su propia voz sino que toman la de Hoc y hablan a través de él. Esa operación permite una fusión narrativa muy particular entre el Yo y el Otro. En esa construcción metafórica, la historieta retoma las narrativas coloniales del siglo XIX donde el héroe blanco no sólo era capaz de compartir experiencias culturales sino de participar en la cultura-otra y en sus costumbres sin perder su propia identidad. La descripción de los marcianos como una noble raza caída en desgracia que debe abandonarse a sus propios recursos durante su larga agonía es también parte de una inquietante tendencia del discurso colonial que emergió inmediatamente después de la independencia. Tal descripción está subrayada por las imágenes de los hombres marcianos que se ven y se visten siguiendo estereotipos basados en el imaginario europeo sobre lo africano y lo asiático como locus de lo exótico y lo sensual. Esas imágenes contrastan con el diseño del héroe, caucásico, fuerte y musculoso, literal y metafóricamente, una máquina perfecta. Esa perfección se manifiesta como una racionalidad moral derivada de una vitalidad que los marcianos aparentan no tener y que le permite a Hoc argumentar (aún en su venganza) en favor de la naturaleza como una forma de retorno a una sacralidad que los propios marcianos no pudieron respetar en su afán tecnologicista. Ese razonamiento casi arielista sería llamativo en medio de la década del setenta si no fuese por dos motivos: primero, es parte de ese anticientificismo finisecular que mencionábamos en las primeras páginas y que, en diferentes versiones, permea todo el campo cultural independientemente de las adscripciones políticas de sus agentes a lo largo de todo el siglo XX. Y en segundo lugar, es un importante ingrediente filosófico de esa conciencia racionalista romántica del krausismo que articula la 
construcción de historietas que, como ésta, son ambivalentes en cuanto a las raíces ideológicas del populismo nacionalista que aparece en otras historietas de ciencia ficción con las que esta historieta dialoga, incluyendo la ya mencionada El eternauta, pero también, Slot Barr (1976) con guión de Ricardo Barreiro (1949-1999) e ilustraciones de Francisco Solano López (1928-2011). Notablemente, aunque parten de perspectivas filosóficas distintas, todas estas historietas comparten una visión populista y autoritaria de lo político cuyas raíces está en la constitución de los sujetos que las pueblan.

En Yo, ciborg, la mirada crítica retoma el imaginario romántico antitecnologicista y se interroga sobre cómo el conocimiento se ha transformado ora en un objeto fetiche ora en un objeto mágico. Esa misma mirada vuelve responsable a la sociedad marciana toda de su propio sino por haber desencadenado el holocausto nuclear que destruyó su planeta. Aquí no hay responsabilidades de estado o de sistemas políticos sino responsabilidades ontológicas. Es por este motivo que toda la historieta es ambivalente en cuanto al valor, uso, y capacidades de la tecnología en general: los terrestres han usado tecnología como parte de sus esfuerzos imperiales; una de las razas marcianas originales es responsable del holocausto nuclear que ha vaporizado toda el agua en el planeta condenándolo a un desastre ecológico sin precedentes, y las otras razas marcianas se han convertido en salvajes incapaces de defender su propio planeta de una invasión porque no tienen memoria de los saberes tecnológicos necesarios para ello. Más grave aún es que la historieta muestra a la tecnología desgajada de todo saber científico, de todo conocimiento o de toda filosofía: como en otras historietas y narraciones de los últimos treinta años hay una absoluta incomprensión sobre la intrínseca relación entre desarrollo científico y desarrollo tecnológico.

El único personaje que tiene algún sentido sobre cómo hacer uso del conocimiento científico y tecnológico sólo está interesado en alimentar su orgullo personal. Este personaje, Zedh, es una cruza entre mago, investigador y científico (cuyo imaginario remite más a los alquimistas medievales que a los investigadores contemporáneos), no le preocupa el destino de su planeta natal y sólo ayuda a Hoc por curiosidad. En este sentido, Zedh encarna y resume el imaginario de la propia historieta sobre la ciencia como una fuerza refractaria a la comprensión (es imposible para todos los personajes articular los saberes en los que se basan los artefactos que usan), violenta y arbitraria en su proceder sobre los sujetos (todos los personajes temen a Zedh, cuyo accionar parece estar organizado en torno a caprichos), y desarraigado de su entorno (Zedh vive literalmente en su propia "torre de marfil", sin hablar ni conectarse con nadie). Si esa lectura asume como propias las ambivalencias de los sectores letrados con respecto al desarrollo científico, también asume una mirada sobre lo científico como un saber amenazante y destructivo, cuya potencia no puede ser controlada. Así Zedh no representa una forma del desarrollo cultural sino una de las múltiples formas de la violencia sobre lo social. El brutal irracionalismo de semejante postura no deja de ser notable en un artefacto que se construye desde el imaginario de la ciencia ficción dura, y parece operar casi a contrapelo de sus más caros supuestos. Desde nuestra perspectiva, es importante subrayar que la historieta no articula solamente la potencialidad negativa de los usos de la ciencia y la tecnología a manos de lo que Dwight Eisenhower llamó en 1961 el complejo industrial militar. Es claro que esa advertencia aparece en la historieta, pero no es la única potencialidad en juego. Al aceptar el declive de su civilización, los marcianos también aceptan otras formas de violencia en su propio terreno. El uso de la 
tecnología y de la ciencia es lo que se condena como corruptor del equilibrio natural del universo: si Hoc quiere ser humano y está dispuesto a matar por ello, si está dispuesto a aniquilar a sus congéneres, o generar una segunda catástrofe ecológica en Marte, es porque intenta reponer lo divino y lo trascendente en una naturaleza que ha sido corrupta por formas de saber que son en sí, la ruptura de lo divino. De este modo, la historieta establece una tensa narrativa donde los valores éticos parecen estallar en todas las direcciones. La fábula intenta una serie de argumentos contradictorios: en tanto los marcianos son las víctimas y los ejecutores de la destrucción científico- tecnológica del planeta, también son tanto una raza vencida como tribus bárbaras, y por eso mismo, deberán/ necesitan morir como precio por los errores de su pasado.

El único ser realmente híbrido de toda la historia, la mujer insecto que ayuda a Hoc a escapar de los mutantes ogr-ur, es el resultado de experimentos de bio-ingeniería cuyos orígenes inciertos también se traducen como el fracaso de saberes científicos ya olvidados. Representada en la historieta como una mariposa con cabeza y brazos de mujer, la mujer insecto evoca las Psychai (las hijas aladas Psyche, entre ellas, Voluptas), aunque aquí, la lectura positivista del mito de Psche y Cupido parece subrayar la transformación de Hoc: de ciborg a humano, de instrumento a espíritu. En las alas de mariposa de la mujer- insecto (es exactamente cómo se lo representa en la viñeta 2 plancha 83), Hoc iniciará la última etapa de su transformación. Los guardias de la mujer insecto no recuerdan su propia historia, ni tienen una comprensión o perspectiva útil sobre el mundo: no saben para qué hicieron a este ser que lee mentes y es tan peligroso que necesita estar encadenado dentro de una bóveda. No es necesario volver sobre el mito de Psyche para comprender que la mujer insecto es el Ello de Hoc y que al liberarla, se libera a sí mismo. Es por eso que la mujer- insecto no tiene intención de revelar ninguna forma de verdad ni de proveer caminos conciliatorios para que Hoc pueda abandonar su venganza. Una vez que es libre, la mujer insecto deja a Hoc para que continúe su venganza contra la humanidad a solas. Simplemente, le muestra el camino de su propia naturaleza y después, desaparece: es ella quien le ofrece la ruta y los elementos de su venganza al revelar que la nave madre terrestre está en órbita sobre Marte (plancha 83). Liberadas las fuerzas naturales (las internas, las externas), el universo retorna a un estado de equilibrio donde no son necesarios saberes o fuerzas para subsistir.

La tensión narrativa se resuelve pues, en torno a la dicotomía que Hoc crea para sí mismo: destruir la humanidad es salvar a Marte; vengarse de la sociedad que lo creó (aún cuando finalmente descubra que Hoc-humano es su propio creador) es la forma más sublime de justicia porque toda otra forma de justicia implica instituciones y, por tanto, reglas de sociabilidad que aquí, están ausentes: si la nueva subjetividad implica una fusión del Yo- Otro con el Nosotros para crear una nueva forma de otredad que se haga cargo de las nuevas formas de Estado (que aquí, por cierto, ni siquiera se discute, sino que se anula), las reglas de sociabilidad internas son innecesarias porque serían el equivalente cultural de una cierta forma de esquizofrenia discursiva.

El tercer grupo que aparece en la historieta son los terrestres. La representación de los terráqueos en una versión casi caricaturesca de las grandes potencias no llega a contrarrestar el peso narrativo del resto de los elementos que hemos discutido hasta aquí. Descriptos como seres belicosos, imperialistas y hasta chauvinistas, los militares de la Tierra intentan extender su dominio en el sistema solar sólo por desarrollar formas arcaicas de propiedad de la tierra. En una guerra altamente sofisticada desde el punto de 
vista tecnológico, ésta parece ser una razón por demás primitiva de expansión económica, incluso para el universo ideológico de la América Latina de los años setenta: es la narrativa de una guerra colonial en medio de la aceleración del proceso de globalización. $\mathrm{Si}$ en parte representa una lectura política y económica a destiempo de procesos mundiales complejos, también representa una lectura de cómo ciertos sectores empiezan a imaginar el lugar de América Latina dentro de esos mismos procesos. La historieta "lee" los riesgos de la globalización en términos de un colonialismo desfasado, donde se culpa a todas las formas de estado del colapso social y cultural (bien por razones internas, bien por razones externas) al mismo tiempo que se celebra su ausencia en la romantización del tribalismo y en la emergente forma de subjetividad que el texto promueve. En este sentido, es notable que la invasión sea en sí misma un acto nihilista ya que para los terrestres no hay beneficio alguno en la ocupación de tierras no cultivables de Marte o en la ausencia de comercio con las sociedades masacradas, por no volver a mencionar que los propios marcianos son incapaces de (re)producir sus avances tecnológicos. Pero al mismo tiempo, esa elección por una guerra pre-industrial permite a la historieta explorar temáticas vinculadas con la alienación a través de la imagen de la Tierra conjurada por soldados, generales y científicos que nunca dudan de sus objetivos ni los cuestionan, quienes están profundamente convencidos de la victoria aún en medio de la derrota, y que son capaces de recurrir a la bomba atómica y a la de hidrógeno como parte de su armamento cotidiano en un artefacto cultural producido originalmente ${ }^{\mathrm{xvi}}$ durante el año de la firma del Acuerdo de No Proliferación de Armas Atómicas. Aún en su búsqueda de salidas a la guerra, los terrestres no pueden imaginar la paz sin una violencia total: la guerra termina cuando Hoc activa un arma ecológica para transformar Marte en un vergel. El mito de una súper- arma ecológica que puede traer la paz universal arrasa con los invasores y restaura la ecología marciana con un argumento muy cercano al de las superpotencias en su justificación del armamentismo.

En la historieta, la aniquilación nuclear tiene dos lados. Cuando se la usa en una guerra interna, trae la destrucción del mundo; cuando se la usa contra enemigos militares restaura la paz. Esta idea también fue explorada en otras historietas argentinas de mediados de los setenta, como fue el caso de la segunda parte del Eternauta (1976). No quiero, por razones de espacio, analizar aquí ni la falacia ni la absoluta inmoralidad de semejante propuesta. Pero sí quiero indicar que junto con una aparente crítica a la ética de la guerra así como una denuncia sobre la agresividad de las superpotencias que intentan subyugar o dominar a otros por la fuerza, también se establece la superioridad moral de quienes toman esas decisiones si lo hacen por "razones de peso". Los terrestres, como Hoc, son determinados e imparables en sus objetivos. Pero la invasión es éticamente una encarnación del mal, mientras que la venganza de Hoc es un intento de restituir el orden al mundo y, por ende, es moralmente, correcta. Por una parte, no hay diferencia alguna entre los invasores militarizados y sus computadoras puesto que comparten la fría lógica de la guerra y de la destrucción, aún a costa de sus propias vidas. Por otra, no parece haber demasiado qué defender en las frías acciones de Hoc, quien finalmente elige asesinar a todos sus congéneres. Todas las elecciones son en blanco y negro: aquí no hay lugar para la duda o la negociación. Esas acciones, sin embargo, son problemáticas porque la ausencia de ley, la permanente recurrencia de la venganza como forma equilibrio social, la presencia constante de la violencia como marcador en todas las relaciones, nos hablan de un universo donde las instituciones mismas no pueden operar y 
donde los proyectos de estado no son ni los remedos de grandes narrativas que alguna vez tuvieron vida. Los movimientos de Hoc en esos espacios nos hablan de una desconfianza en la capacidad de los sujetos para formar sociedades diversificadas, que apelan al diálogo y a la búsqueda de consenso. Más bien, este nuevo Otro subraya la formación de una subjetividad nacional construida desde la coerción y sobre nociones de absoluto que están en profunda deuda con el maniqueísmo autoritario que atraviesa el siglo XX.

\section{Conclusiones}

Puesto que las versiones de Yo, ciborg de 1978 y 1991 son idénticas, debemos asumir que la propuesta ideológica original se mantuvo inalterada y constituye el esqueleto arquitectónico de la historieta y que la lectura de la historieta como una respuesta de resistencia a la dictadura tiene poco que ver con las operaciones que sostienen su armazón ideológico, aún cuando haya algunos elementos que sustenten débilmente esta lectura. Si como decía Derrida, toda forma de monstruosidad nos hace percibir la diferencia, los monstruos de la ciencia ficción argentina, tan comprometida con la reflexión ideológica, se convierten en el locus de discusiones en torno a las las capacidades, las contradicciones y los límites de agendas ideológicas que debaten conceptos de diversidad en estado de ruptura, transformación, o colapso. Al abarcar todas las posibles facetas de lo Otro y proveerlo de múltiples posibles identidades que subrayan la distinción como punto de partida para el diálogo, historietas como Yo, ciborg organizan una agenda discursiva que, en sus inicios, parecen operar a contrapelo del sentido común del campo cultural. Pero es necesario indagar qué nos dicen y de qué quieren hablar los monstruos, los extraterrestres y las razas extrañas de la ciencia ficción. Estos sujetos-otros articulan formas identitarias que permiten la articulación de lo político no como un núcleo de ideas fuertes sino como una suerte del pasar de las acciones que formulan como ética aquello que es simplemente reactivo. Es por este motivo que se hace necesario preguntarse contra qué y por qué parecen emerger este tipo de narrativas y artefactos con notable violencia a partir de la década de 1970. De ningún modo hemos asumido que existe una directriz común en los debates ni que los mismos sean funcionales a la ciencia ficción como modalidad ni que sus artefactos operen desde las mismas premisas ideológicas. Sin embargo, aún en sus diferencias, puede observarse que con cierta consistencia emerge una discursividad donde se plantean las serias dificultades que existen para que la diversidad de lo Otro (encarnado en lo monstruoso, lo híbrido o lo extraño) quepa en la articulación de modelos ideológicos que asumen formas identitarias fuertes en la conformación de los sujetos que los conforman como programas. Con ser fluidas, las modulaciones sobre el sujeto- masa y/o el sujeto- muchedumbre (dependiendo del período y de la perspectiva) aparece ya constituido como una singularidad donde se apoyan formas culturales refractarias a la diferencia. Yo, ciborg, como las otras historietas aquí mencionadas, narran la desaparición del estado y de toda forma institucional como un principio constitutivo de la libertad. Pero el texto se desmiente a sí mismo: esa ausencia se reemplaza por otras formas organizativas que niegan las diferencias. Así pues, la presencia misma de una otredad compleja muestra las contradicciones (y hasta la imposibilidad) de esos modelos ideológicos para incorporar y aceptar la diversidad y la pluralidad como parte intrínseca de sus programas. Que lo que emerge de esa reflexión sea exitoso políticamente es otra cuestión: lo que nos interesa 
aquí es cómo aparece esa problemática porque además, esos seres muestran el modo sesgado en que se evalúan sociedades abiertas desde discursos donde se desarrollan crecientes grados de autoritarismo. Así pues, lo monstruoso parece operar un cierto barómetro de lo político desde temas caros a las narrativas fundacionales argentinas que subsistieron de un modo u otro a lo largo de más de cien años. En el espejo cóncavo de lo monstruoso, temáticas como la relación entre sociedad y estado, entre ciencia y desarrollo, entre identidad y nación, o entre ética y moral, revelan nuevas facetas de lo político y, por eso, tienen un importante espacio de producción en la ciencia ficción. Si bien estos temas eran parte de reflexiones que afectaron todo el campo cultural, como hemos visto, en la ciencia ficción se vuelven transparentes las bases ideológicas de las narrativas centrales del campo cultural porque lo monstruoso hace transparente la ontología de esos debates.

\begin{abstract}
Notas
' Si bien la ciencia ficción tardaría todavía años en sacudirse la etiqueta de la marginalidad, los años setenta son, extrañamente, años de bonanza editorial para la historieta porque empieza a recuperarse de los desastres editoriales de la década anterior, por un lado, y por otro, porque se convierte en uno de los pocos espacios contestatarios de consenso a la dictadura: 1978 vio la primera publicación de revistas como Humor de Editorial de la Urraca. Es entonces discutible la cuestión de la marginalidad, pero por razones de espacio no podemos hacerlo aquí y por ende asumimos (aunque con salvedades) la propia perspectiva de sus propios creadores. Sería cuestión de otro trabajo analizar este tema.

ii Vehículo (y en cierta forma la búsqueda que emprende Hoc, así como sus consecuencias) es vagamente reminiscente de las así llamadas "naves generacionales" o las "arcas interestelares" que aparecen en novelas como Non-Stop (1958) de Brian Aldiss o Captive Universe (1969) de Harry Harrison. El espacio mecánico se convierte en universo y la vida regulada por las necesidades (en este caso militares) se ha naturalizado como forma de saber que articula las relaciones entre los sujetos. En cierta forma, Vehículo organiza la metáfora de una sociedad distópica que se ha salido de sus propios carriles y no puede siquiera imaginar formas de sociabilidad constreñidas por la rigidez de sus propias reglas.

iii La influencia de la filosofía de Karl Christian Friedrich Krause (1781-1832) en Argentina tiene sus raíces en el espiritualismo que acompañó tanto al romanticismo como a cierto pensamiento positivista durante la segunda mitad del siglo XIX. Aunque su ascendiente fue algo difuso, sus huellas aparecen en buena parte del pensamiento ilustrado así como del pensamiento liberal católico finiseculares y se extiende hasta bien entrado el siglo XX, particularmente dado el eclecticismo con que se entendieron y apropiaron diversas corrientes de pensamiento europeo. Ardiente defensor de los derechos de las mujeres y los niños, Krause también creyó que la naturaleza no era sólo un recurso a ser explotado sino que que debía ser protegida por cuanto profesaba una forma de panteísmo cristiano. Pero su más importante contribución al pensamiento latinoamericano fueron sus difusos principio éticos, ya que proponía una suerte de perfeccionamiento del Hombre a través de la Razón en la crónica de la historia. Las sociedades, para Krause, debían organizarse en la solidaridad y en la armonía: era un idealismo sin referencias a la economía o lo social que resultaba particularmente atractivo en la Argentina convulsionada por los nuevos movimientos sociales del fin de siglo XIX. Así pues, el krausismo vino a proveer un vago subtexto ético a muy diversas y hasta enfrentadas corrientes políticas, para finalmente hacer nido en los debates de lo que Roig ha llamado la "burguesía liberal conservadora de carácter progresista", de la cual el yrigoyenismo sería particular representante en las décadas del veinte y treinta del siglo siguiente. Si bien el pensamiento krausista había cumplido su ciclo a mediados de la década del treinta, siguió siendo un referente importante para sectores que veían en el creciente desarrollo capitalista de la Argentina una amenaza a imaginarias virtudes nacionales que acabarían por cobrar cuerpo en el discurso sobre el ser nacional: no es casual, pues la influencia de Ortega
\end{abstract}


y Gasset en este proceso ni que ésta mantuviera viva, en parte, las referencias al krausismo. Tanto Roig como Sebreli coinciden en señalar que el krausismo pervive en el discurso populista y nacionalista argentino adoptando nuevas formas discursivas, pero manteniendo su actitud irracionalista y antiintelectual. (Todas las referencias al krausismo del presente trabajo provienen de:

Arturo Andrés Roig. Los krausistas argentinos, Buenos Aires, Ediciones El Andariego, 2006.

Juan José Sebreli. Crítica de las ideas políticas argentina, Buenos Aires, Editorial Sudamericana, 2002.

Ricahrd Gott. Karl Krause and the Ideological Origins of the Cuban Revolution. London. University of London, Institute of Latin American Studies Occasional Papers, 2002).

${ }^{i v} \mathrm{He}$ analizado en otros trabajos este proceso y no quisiera repetirme. Ver Silvia Kurlat Ares: Para una intelectualidad sin episteme. El devenir de la literatura argentina (1974-1989), Buenos Aires: Editorial Corregidor, 2006

${ }^{\vee}$ Los tres tomos de La voluntad (1998- 2006) de Martín Caparrós y Eduardo Anguita son quizá uno de los ejemplos más densos de esas operaciones.

vi En este sentido, baste rastrear los debates en las revistas del exilio mexicano, como el caso de Controversia, donde aparecen las primeras polémicas en torno a la reformulación democrática del peronismo puesto que suponía una re- evaluación del sujeto político y social que conformaba el "pueblo".

vii Si alguna duda cupiese sobre los resultados de esa operación, baste remitirse al himno del programa de televisión 6.7.8, "La mierda oficialista" de Carlos Barragán, donde se organizan los núcleos de reconocimiento de ese Otro que ahora detenta el poder como una forma de oposición a imaginarios y no tan imaginarios detractores de sectores que parecían no tener espacio en el debate nacional. Para el lector interesado, la canción está disponible en varios sitios en la web.

viii Ver mi trabajo sobre el tema, Silvia Kurlat Ares:"La utopía indígena en la literatura argentina de la última década: el caso de Ema, la cautiva de César Aira", in Ciberletras. Revista de Crítica Literaria y Cultura, Vol. 5 (August 2001), Web http://www.lehman.cuny.edu/ciberletras/index_files/v05.html

${ }^{\mathrm{ix} C o m o}$ ejemplo paradigmático de esta construcción puede pensarse en los argumentos de la segunda camada del revisionismo histórico en la Argentina de la década del treinta. Historiadores como José Ma. Rosa o los hermanos Irazusta buscaron reponer en la narrativa canónica de la historia sujetos y eventos que consideraban los verdaderos depositarios del así llamado ser nacional. Aunque esas versiones de la historia fueron incorporadas en el discurso político, sus contribuciones no fueron ni tan fidedignas ni tan acertadas en su evaluación del devenir socio-económico del país. Historiadores como Tulio Halperín Donghi se han ocupado de analizar esos debates historiográficos.

Tulio Halperín Donghi: Argentina en el callejón, Buenos Aires: Editorial Ariel, 2006

× En rigor de verdad, es en las tres versiones originales de El Eternauta (1957-1959/ 1969/ 1975-1976) con guión de Héctor G. Oesterheld (1919-1978?) donde esos elementos articulan un nudo fuerte en torno a la discursividad del nosotros que organiza el discurso político de los siguientes cincuenta años. Aquí, se organiza, para decirlo de algún modo, el corolario ideológico de tal apuesta, es decir, la fusión del nosotros con el otro de la muchedumbre.

xi El tema mítico del asesinato del viejo rey como inicio de un nuevo sistema o como prolegómeno del advenimiento de una sociedad más justa queda anulado en la historieta cuando Hoc mantiene el viejo sistema político de Sep Namú sin alteraciones, primero, y más tarde, cuando toda la sociedad es aniquilada por bombas neutrónicas y desaparece. Lo que invadirá el planeta entero, en el final, es una naturaleza famélica de venganza que canibalizará todo lo humano, haciendo claro que la síntesis krausista de hombre y naturaleza permite revertir el sistema todo a prácticas judiciales pre- institucionales (la doble venganza de Hoc y de Marte) y la anulación del tiempo histórico, como veremos en las próximas páginas.

xii En este sentido, y como ya he mencionado, la historieta está trabajando a contrapelo de lecturas del ciborg que harían más tarde feministas como Donna Haraway o de las lecturas que imaginan la idea del simulacro como espejismo de lo real en una línea cercana a Baudrilliard, puesto que aquí el sujeto ciborg es una negación e intenta un retorno intenso a una humanidad pre-social, como sugiere la imagen final de la historieta, que muestra a Hoc solo, abandonando toda forma de civilización y sociabilidad después de haber restaurado el orden primordial del cosmos a través de una serie de actos que citan la Biblia: el orden natural de Marte sólo se restaura a través de una inundación que dura siete días y siete noches (plancha 85). Más aún: Hoc es un sujeto claramente masculino y al recuperar su cuerpo biológico destruye toda argumentación en favor de los cuerpos-sin-madre. (¿Es esto un nombre del cómic?)

xiii Para un análisis del criterio de identidad biológica ver DeGrazia, David: Human Identity and Bioethics, Cambridge: Cambridge University Press, 2005 
xiv La historieta acusa recibo del fin de los proyectos de modernidad en el período de la dictadura, cuestión que fue ampliamente debatida en los años posteriores a la transición democrática. Es interesante notar que lo que se propone como nuevo sujeto es una versión muy peculiar del superhombre nieztcheano y la anulación de la heterogeneidad como germen de una respuesta hacia la salida democrática.

xv La famosa controversia de Valladolid de 1550 fue una confrontación sobre la legitimidad jurídica de la conquista de América entre Fray Bartolomé de Las Casas y Ginés de Sepúlveda. Las Casas argumentó en contra de la conquista partiendo de la articulación del mito del buen salvaje, al aducir un modelo de ética natural en los indígenas americanos que lo llevó a defender la superioridad moral de los últimos frente a los europeos. Para un resumen de la discusión y de sus resultados ver:

Ana Manero Salvador. "La controversia de Valladolid: España y el análisis de la legitimidad de la conquista de América." Revista Electrónica Iberoamericana Vol. 3 n 2 (2009) Web. Julio 102013.

$\langle$ http://www.urjc.es/ceib/investigacion/publicaciones/REIB_03_02_A_Manero_Salvador.pdf $\rangle$

xvi Es notable el número de textos argentinos de ciencia ficción que imaginan la vuelta a cero del contador histórico a partir de un desastre nuclear así como una suerte de liviandad con que se trata el tema del holocausto nuclear en las historietas de ciencia ficción de los sesenta y setenta. Oesterheld llegó a meditar sobre algunos aspectos éticos de los resultados de tales apuestas en algunos de sus textos de los años sesenta, particularmente en un relato en primera persona titulado "Hiroshima" (1962), contado desde la perspectiva de la ciudad atrincherada para la guerra y la resistencia contra la invasión norteamericana. Todo el discurso gira en torno a cómo los bombardeos afectaron a los ciudadanos comunes en las calles: madres, niños, conductores de tranvías, sobrevivientes, refugiados. Aquí, a diferencia de la historieta que nos ocupa, las responsabilidades éticas y morales parecen desvanecerse completamente ante la magnitud del desastre. Sin embargo, en todos estos artefactos, hay una notable imbricación discursiva que cruza las aspiraciones del nacionalismo de diversos sectores, incluidos facciones militares que abogaban por el desarrollo de agua pesada en Argentina (en especial durante los años de la dictadura), el populismo que veía en el capitalismo una forma de traición a sus raíces identitarias (el mentado "ser nacional") y los usos "justos" de la guerra nuclear. Para un ejemplo de este tipo de lecturas en la ciencia ficción argentina, "El día del juicio" de Solano López y Barreiro es claro: el hijo bastardo de Pablo Escobar, al heredar el Cartel de su padre, ataca EE.UU. con bombas nucleares en una doble venganza personal y política que de alguna manera parece espejar algunas de las operaciones ideológicas de Yo, ciborg.

\section{Obras citadas}

Barreiro, Ricardo y Francisco Solano López. El día del jucio. Buenos Aires: Doedytores, 2009.

Barreiro, Ricardo, y Francisco Solano López. Slot-barr. Buenos Aires: Colihue, 2001.

Beasley-Murray, Jon. Posthegemony: Political Theory and Latin America. Minneapolis: University of Minnesota Press, 2010.

Brown, J. Andrew. "Humanismo Cyborg: El Letrado Posthumano an América Latina." Revista De Crítica Literaria Latinoamericana. (2008): 19-32.

Brown, J. Andrew. Cyborgs in Latin America. New York: Palgrave Macmillan, 2010

Capanna, Pablo. Historia De Los Extraterrestres: Los Mitos, Las Fábulas, Los Miedos, Los Disparates Y Los Intentos Cientificos Por Encontrarlos. Buenos Aires: Capital Intelectual, 2006.

Castells, Manuel. The Power of Identity. Malden, Mass: Blackwell, 1997/2004.

Castells, Manuel. 'Epilogue: informationalism and the network society', in Pekka Himanen, The Hacker Ethic and the Spirit of the Information Age, London: Secker \& Warburg, 2001. 
DeGrazia, David: Human Identity and Bioethics, Cambridge: Cambridge University Press, 2005.

Freedman, Carl H. Critical Theory and Science Fiction. Hanover: Wesleyan University Press, 2000.

Grassi, Alfredo y Lucho Olivera. Yo, Ciborg. Buenos Aires, Editorial Record, Suplemento de Skorpio, 1991.

Gott, Ricahrd. Karl Krause and the Ideological Origins of the Cuban Revolution. London. University of London, Institute of Latin American Studies Occasional Papers, 2002.

Hayles, N. Katherine. How We Became Posthuman. Virtual Bodies in Cibernetics, Litertaure, and Informatics, Chicago \& London, The University of Chicago Press, 1999.

Haraway, Donna J. Simians, Cyborgs, and Women: The Reinvention of Nature. New York: Routledge, 1991.

Jacquart, Danielle: De la science en literature à la science-fiction, Paris: Editions du CTHS, 1996.

Jameson, Frederic: Archaeologies of the Future. The Desire Called Utopia and Other Science Fictions, London/ New York: Verso, 2005.

Kurlat Ares, Silvia G.“ Máquinas infernales: medios de transporte en la cultura argentina a lo largo del siglo XX", en Fernando Reati (Comp.): Autos, trenes y aviones. Medios de transporte, modernidad y lenguajes artísticos en América Latina, Córdoba, Argentina: Alción Editora, 2011.

Locke, Simon. "Fantastically Reasonable: Ambivalence in the Representation of Science and Technology in Super-Hero Comics." Public Understanding of Science. 14.1 (2005): 25-46.

Markley, Robert: Dying Planet. Mars in Science and the Imagination, Durham: Duke University Press, 2005.

Oesterheld, Héctor G.. El Eternauta y otras historias. Buenos Aires: Editorial Colihue, 1997.

Roig, Arturo Andrés. Los krausistas argentinos, Buenos Aires, Ediciones El Andariego, 2006.

Rosenberg, Daniel y Susan Harding (Editores): Histories of the Future, Durham: Duke University Press, 2005.

Sebreli, Juan José. Crítica de las ideas políticas argentina, Buenos Aires, Editorial Sudamericana, 2002.

Seed, David (Editor): Imagining Apocalypse. Studies in Cultural Crisis, London/ New York: St. Martín's Press, 2000.

Suvin, Darko: Metamorphoses of Science Fiction, London/ New Haven: Yale University Press, 1979. 